\title{
The shallow boreholes at The AltotiBerina near fault Observatory (TABOO; northern Apennines of Italy)
}

\author{
L. Chiaraluce ${ }^{1}$, C. Collettini ${ }^{1,2}$, M. Cattaneo ${ }^{1}$, and G. Monachesi ${ }^{1}$ \\ ${ }^{1}$ Istituto Nazionale di Geofisica e Vulcanologia, Rome, Italy \\ ${ }^{2}$ Università degli Studi di Roma, La Sapienza, Rome, Italy \\ Correspondence to: L. Chiaraluce (lauro.chiaraluce@ingv.it)
}

Received: 5 February 2014 - Revised: 7 April 2014 - Accepted: 9 April 2014 - Published: 29 April 2014

\begin{abstract}
As part of an interdisciplinary research project, funded by the European Research Council and addressing the mechanics of weak faults, we drilled three 200-250 m-deep boreholes and installed an array of seismometers. The array augments TABOO (The AltotiBerina near fault ObservatOry), a scientific infrastructure managed by the Italian National Institute of Geophysics and Volcanology. The observatory, which consists of a geophysical network equipped with multi-sensor stations, is located in the northern Apennines (Italy) and monitors a large and active low-angle normal fault.

The drilling operations started at the end of 2011 and were completed by July 2012. We instrumented the boreholes with three-component short-period $(2 \mathrm{~Hz})$ passive instruments at different depths. The seismometers are now fully operational and collecting waveforms characterised by a very high signal to noise ratio that is ideal for studying microearthquakes. The resulting increase in the detection capability of the seismic network will allow for a broader range of transients to be identified.
\end{abstract}

\section{Introduction: scientific background}

Scientists' ability to integrate geological, seismological and laboratory observations related to earthquakes and faulting are essential for opening new paths of discovery and increasing our understanding of fault mechanics. The main difficulty in reconciling multidisciplinary observations is the scale dependence, which characterises the underlying physical processes that are inherent to each discipline. To tackle this challenge, the main prerequisites are the availability of highresolution data and access to state-of-the-art research infrastructure that allow for the analysis of innovative and original data sets.

To lower the minimum earthquake detection threshold and to enhance the resolution of the signals recorded by our seismic network, we decided to build a seismological antenna at depth. These field observations complement the laboratory data produced by a newly built biaxial rock deformation apparatus within a pressure vessel (Collettini et al., 2014) capable to record acoustic transients emitted from deforming rock samples.
The instrumented boreholes are part of The AltotiBerina near fault ObservatOry (TABOO; http://taboo.rm.ingv. it/; Chiaraluce et al., 2014), a scientific infrastructure managed by INGV (Istituto Nazionale di Geofisica e Vulcanologia). The infrastructure consists of sites equipped with multisensor stations (seismometers, GPS, geochemical and electromagnetic sensors), devoted to the monitoring of a $60 \mathrm{~km}-$ long active normal fault system located along the northern Apennines of Italy (Fig. 1).

The fault system monitored via TABOO is dominated by the Alto Tiberina fault (ATF), a low-angle normal fault dipping in the range of $15-20^{\circ}$. In the same area, moderate to large earthquakes seem to nucleate on steeply dipping normal faults antithetic to ATF (Fig. 1). The ATF is oriented at high angle to the maximum vertical compressive stress, $\sigma_{1}$, and is therefore severely misoriented within the active stress field (Collettini and Barchi, 2002). The ATF, as many other low-angle normal faults (LANF) around the world (Collettini et al., 2011), formed as a gently dipping structure and is characterised by a high and constant rate of microseismic activity (Chiaraluce et al., 2007). These observations, collected in the 


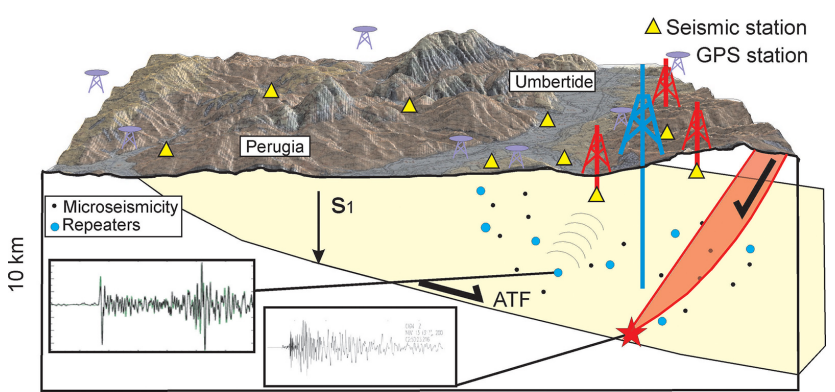

Figure 1. Illustration showing the geological and geophysical characteristics of the TABOO test site.

last ten years, pose numerous questions such as the following: how can a LANF initiate at a high angle to the maximum compressive stress? What are the physical properties of the fault rocks? Does the fault generate only microseismicity, by the reactivation of localised fault patches, or also large earthquakes with a magnitude of up to 7 that can break the entire fault surface? To answer these questions, we have developed an interdisciplinary research project addressing the mechanics of seismic vs. aseismic deformation.

Here we report on site selection and instrumentation, and discuss the quality of background data.

\section{Site selection}

We selected our chosen sites for the seismological antenna (Fig. 2; a zoom of the area inside the box is found at the bottom left) for two reasons. First, the location of a nearby deep borehole (Mt. Civitello; $5.6 \mathrm{~km}$ depth) that is one of the deepest wells drilled by the Italian National organisation for Hydrocarbons (ENI). Borehole and laboratory $P$ wave velocities (Trippetta et al., 2010, 2013) have been integrated with $P$ wave velocities obtained from best migration analysis of the seismic reflection profiles (Mirabella et al., 2011) and earthquake data collected by TABOO (Latorre et al., 2014) to develop a detailed one-dimensional velocity model for earthquake locations (Table 1).

Furthermore, observations of microseismic activity (including repeating earthquakes), which might be related to the ATF, nucleate at $5 \mathrm{~km}$ depth. Second, the ATF is a potential target for a deep-drilling project (Multidisciplinary Observatory and Laboratory of Experiments along a drilling in central Italy; MOLE). An ICDP (International Continental scientific Drilling Program)-funded workshop was held in May 2008 (Cocco et al., 2009) to analyse its scientific and technological feasibility. One major outcome of the workshop was a determination that to sample uncompromised fault rock from seismogenic depth would require a borehole with a total depth of 5-6 km. This borehole would target the source regions of repeating microearthquakes and sample those fault rocks. An array of seismometers at depth, producing low

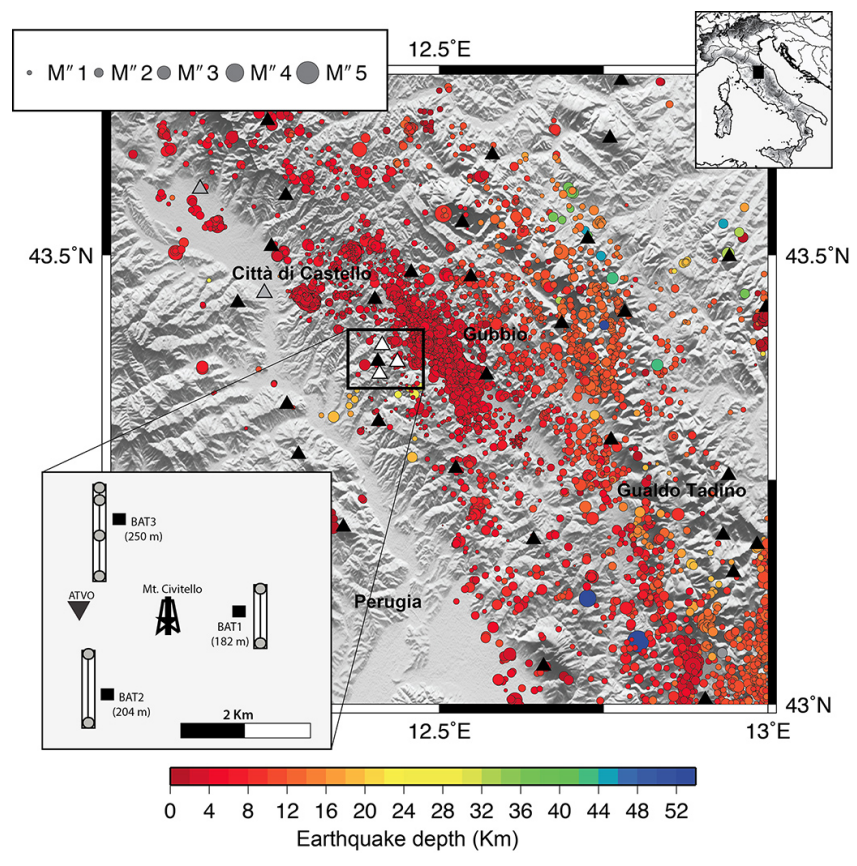

Figure 2. Map of the study area. Circles show the $\approx 12000$ earthquakes that occurred from July 2012 through December 2013. They have been both scaled in size according to the local magnitude $\left(M_{\mathrm{L}}\right)$ of the events and colour-coded based on their hypocentral depth. The black triangles represent surface stations while the white and grey triangles show borehole stations. At the bottom left, we show a zoom of the area where the three boreholes (BAT1, BAT2 and BAT3) are located. The black icon in the centre is the location of the Mt. Civitello deep borehole while the upside-down triangle is a permanent station (ATVO).

noise signals, will monitor microseismic events that occur at a depth shallower than $5 \mathrm{~km}$.

The geometry of our boreholes forms a triangle centred on the deep borehole (Mt. Civitello in the bottom left zoom of Fig. 2) with a mean distance between the sites of about $3 \mathrm{~km}$.

\section{Drilling operations and borehole instrumentation}

All boreholes are hosted in the same lithology: the Miocene Marnoso Arenacea (marly-arenaceous turbidites in Table 1) formation. Around the seismological antenna, this formation consisting of marls and arenaceous rocks is characterised by an average thickness of about $1 \mathrm{~km}$. Under ambient pressure, the density of the lithology measured in the laboratory is about $2.46 \mathrm{~g} \mathrm{~cm}^{-3}$ and the connected porosity ranges from 2.2 to $13.8 \%$ (Trippetta, personal communication, 2014).

The holes were drilled with a traditional rotary drilling technique and did not include any coring operations. We used drill rods of diverse diameters and weights. Drill collars were connected to the drill bit to keep the drill string straight. We used a drill bit designed for medium-hard rock types that had 
Table 1. Average $P$ wave velocity for the lithologies encountered in the Mt. Civitello borehole.

\begin{tabular}{lcccc}
\hline$P$ wave velocity $\left(\mathrm{km} \mathrm{s}^{-1}\right)$ & Borehole & Laboratory & Seismic profiles & Seismology \\
\hline Marly-arenaceous turbidites & 4.0 & 4.0 & 4.0 & 4.0 \\
Carbonates & 5.6 & 6.0 & 5.5 & 5.5 \\
Triassic evaporites & 6.3 & 6.4 & 6.1 & 6.1 \\
\hline
\end{tabular}

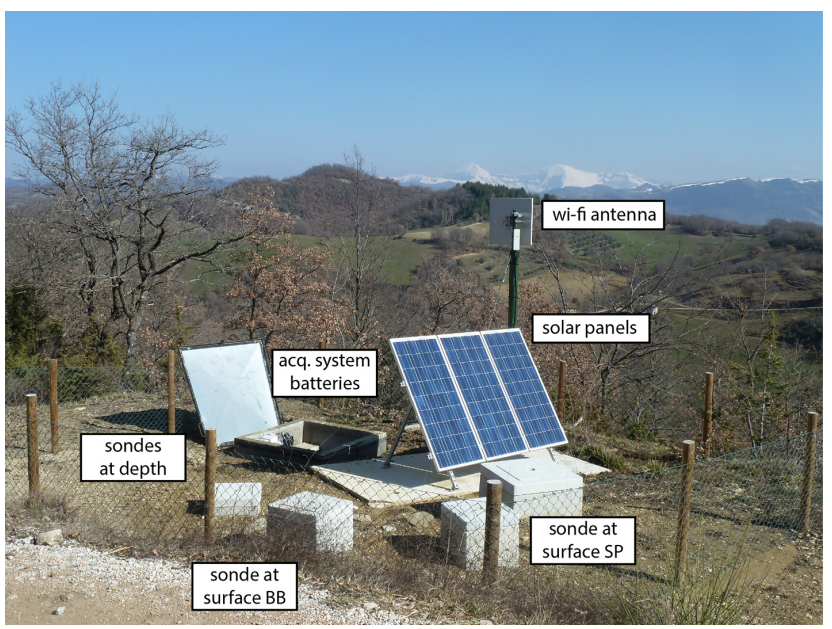

Figure 3. An example of a site hosting the seismic instruments: BAT2 station. The solar panels provide power to the acquisition and transmission system (Wi-Fi antenna). In the case of a lack of sun, there is a set of batteries that can power the station for about ten days. There are three concrete boxes accommodating the broadband (BB) and short-period sensors located at the surface plus the wellhead with the cable connecting the seismometer at depth with the acquisition system.

a diameter of $165.1 \mathrm{~mm}$ (6 $1 / 2 \mathrm{in}$.). The rate of penetration was generally quite regular, ranging from 2.65 to $3.75 \mathrm{~m} \mathrm{~h}^{-1}$.

To ensure a better insulation of the sensor from surface noise and a better coupling of the seismometer with the surrounding rocks, we decided to case only the first $9 \mathrm{~m}$ of the boreholes with a temporary iron casing $(220 \mathrm{~mm})$.

Due to the local lithology conditions and the stability of the boreholes, we were able to avoid casing in two sites (BAT1 and BAT2). After the completion of drilling, the instruments were lowered and cemented in, with cement filling the borehole to about $10 \mathrm{~m}$ above the sensors. The cement was mixed with rock salt in order to increase the settling time. The remaining portions of the boreholes were filled with sand, to avoid cable torsion in the case of large seismic events.

At the third site (BAT3), we encountered problems while drilling. At about $180 \mathrm{~m}$ depth, we experienced near total loss of the drilling fluid into the formation. We suspect that this probably occurred due to the intersection of the borehole with a highly fractured zone. For this reason, we installed a plastic casing (polyvinyl chloride, PVC) within the entire borehole to avoid loss of the borehole.

The three boreholes were drilled to different total depths: $182 \mathrm{~m}$ (BAT1), $204 \mathrm{~m}$ (BAT2) and $250 \mathrm{~m}$ (BAT3). This difference was by design as we halted drilling once we encountered less fractured, more competent lithologies, at a depth of around $200 \mathrm{~m}$ in BAT1 and BAT2. Each borehole is equipped with a sensor at the bottom of the hole and at the surface, while the deepest borehole (BAT3) has a vertical array, with a sensor every $100 \mathrm{~m}(50,150$ and $250 \mathrm{~m})$.

The sensors consist of three-component short-period (SP) seismometers with a natural frequency of $2 \mathrm{~Hz}$. The signal is sampled at $500 \mathrm{~Hz}$. The instruments are passive geophones installed inside $1.06 \mathrm{~m}$ long steel housing with a diameter of $8.8 \mathrm{~cm}$ and a weight of $30 \mathrm{~kg}$. We decided to install SP passive instruments as we mainly deal with small to moderate earthquakes that have a more interesting bandwidth toward the higher frequencies. A sampling rate of $500 \mathrm{~Hz}$ allows for a complete recording up to $200 \mathrm{~Hz}$. Moreover, by using passive sensors, we do not need a power supply in the boreholes, which can be a source of complications for long-term experiments.

The three sites have also been equipped with additional short-period and broadband seismometers positioned at the surface (SP and BB respectively in Fig. 3, where we show a picture of BAT1 site) to allow for a better comparison and association between data collected by both seismometers at depth and the other stations of the TABOO network.

The TABOO network has two additional short-period seismometers installed inside shallow boreholes further to the north (grey triangles in Fig. 2). They were installed by INGV in early 2000. As these sensors are installed within the unconsolidated alluvial sediments of the Tiber valley and are mainly used for the analysis of site effects, they do not produce high-quality data. Our decision to drill in the Marnoso Arenacea formation was based on this experience.

Power at the remote sites is supplied by solar panels. The dedicated transmission system is composed of a Wi-Fi antenna linked to a radio backbone (Fig. 3) and transmits data in real time to the INGV acquisition centre located about $80 \mathrm{~km}$ away.

The three sites are now completely operative and record high-quality data characterised by a high signal to noise ratio $(\mathrm{S} / \mathrm{N})$. They enhance the detection capability of the local area down to negative magnitude events (Chiaraluce et al., 2014). In Fig. 4a and b, two power spectral densities from 

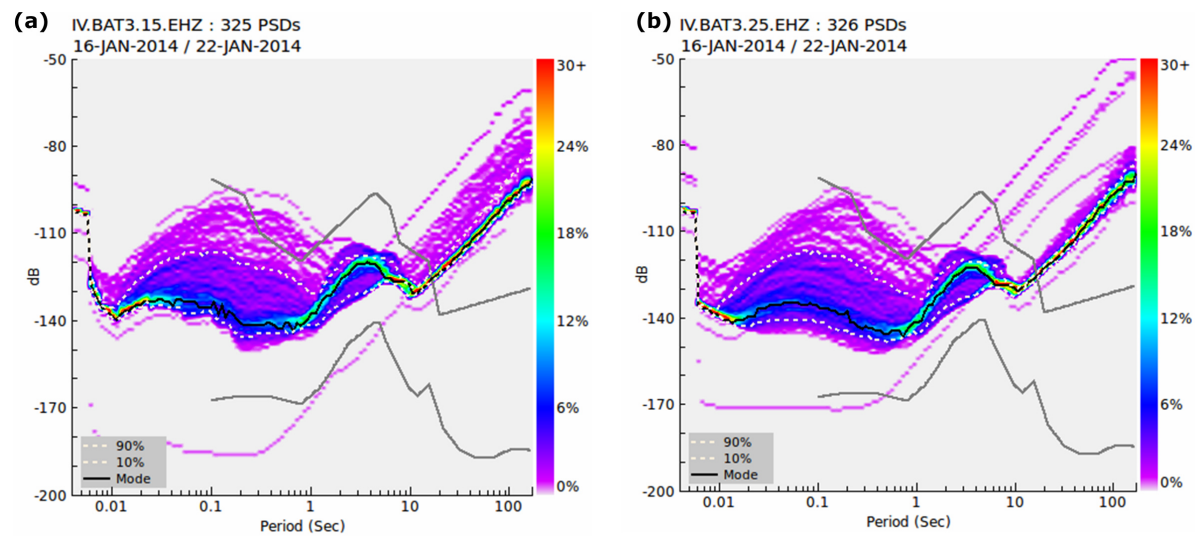

Figure 4. Power spectral density computed from data recorded during one week at BAT3 at a depth of 150 (a) and 250 (b) m.

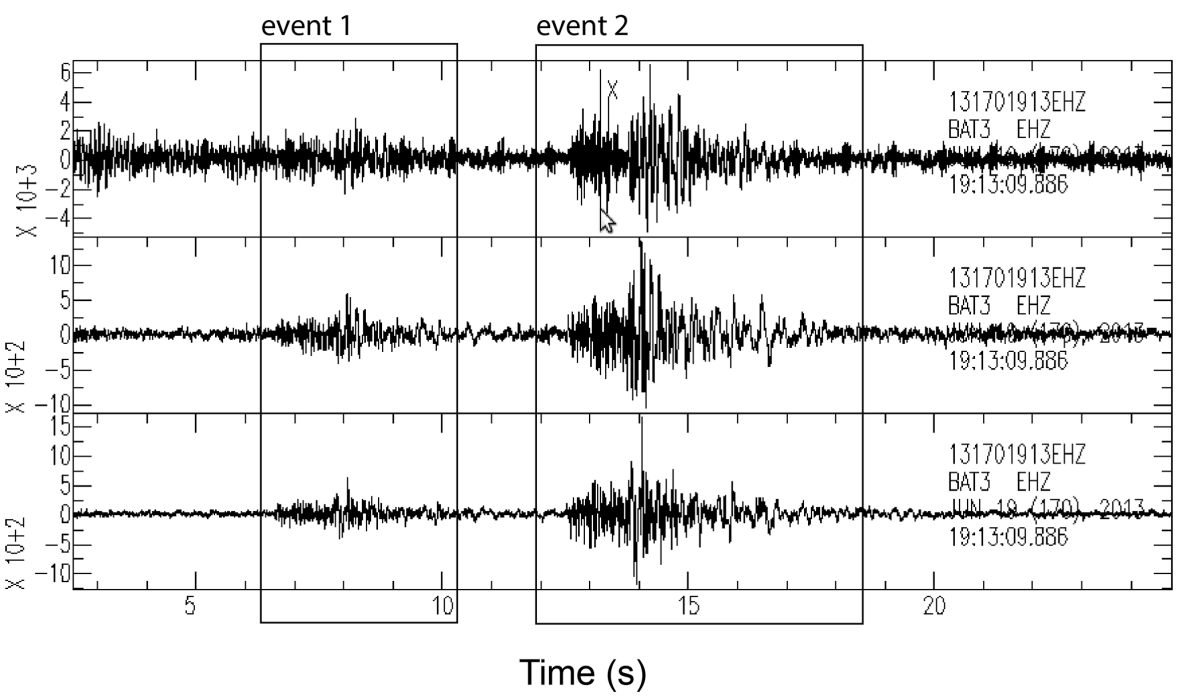

Figure 5. Two small earthquakes recorded at BAT3. Top trace: surface sensor. Middle trace: sensor at $150 \mathrm{~m}$. Bottom trace: bottom sensor $(250 \mathrm{~m})$.

one week of recording at station BAT3 by the sensors installed at a depth of 150 and $250 \mathrm{~m}$ are shown. It is evident that at high frequencies, the noise level is significantly reduced in the deeper sensor. Also, the high number of earthquakes (bell-shaped spectra in the period band 0.01-10s) recorded by both sensors is significant.

Figure 5 compares the recording of two low-magnitude earthquakes (local magnitude -1.0 and -0.6) for station BAT3 by sensors at the surface, $150 \mathrm{~m}$ depth and $250 \mathrm{~m}$ depth. It is evident that the deepest sensor is suitable to record even smaller earthquakes, while at the surface only the larger event is recognisable and characterised by a more complex waveform.

\section{Results and conclusions}

Figure 2 shows a map view of the seismicity we gathered with the TABOO seismic network which includes seismic stations at the surface (black triangles) and is complemented by the stations at depth (white and grey triangles). We indicate the position of BAT1, BAT2 and BAT3 (white triangles inside the black box highlighting the zoomed-in area in Fig. 2) relative to both the entire network and the seismic activity. About 12000 earthquakes, $-1.2<M_{\mathrm{L}}<3.9$, were recorded from July 2012, when all the three borehole stations were connected to the acquisition system, through to December 2013. The contribution of the borehole stations to the network is highly significant. In the cited time span, $33520 P$ wave arrival times were obtained from the borehole recordings of the deepest sensor in each well. The capability to record more than $90 \%$ of the events that occurred in the area also testifies to the robustness of the equipment and study site.

The earthquakes have been colour-coded based on their hypocentral depth to point out the location of seismicity and the array relative to the ATF geometry. The boreholes are 
positioned above the shallow seismicity that nucleates on the ATF at about $5 \mathrm{~km}$ depth. Our expectation is to detect nearly $100 \%$ of the microearthquakes occurring on the ATF plane at shallow depths. As a consequence, the costs of a potential deep-drilling experiment, would greatly decrease.

We are planning additional instrumentation of TABOO including the construction of a strain-metre array. The aim is to enlarge the spectrum of the observed deformation mechanisms. In this way we can additionally reduce the gap between natural and experimental earthquakes and try to improve our understanding of the physics behind the process.

Our end goal is to compare natural and lab observations. With the borehole seismometers we are almost able to record the full range of (high) frequencies characterising the source of small earthquakes occurring in situ on sub-metre-scale faults (e.g. local magnitude -1.0 in Fig. 5). While in the laboratory, we will reproduce microearthquakes on relatively large $20 \times 20 \mathrm{~cm}^{2}$, fluid-rich experimental faults sheared at in situ boundary conditions.

Acknowledgements. We thank Maria Jose Jurado and an anonymous reviewer for their comments. We also thank $\mathrm{T}$. Wiersberg and U. Harms for their valuable observations and B. Carpenter for reading the last version of this report.

We are grateful to G. Costoncelli, A. Reale and the GEOTEC field crew for their support during drilling. We are indebted to P. Malin, M. Hogg, E. Shalev and the IESE staff for their assistance and suggestions while instrumenting the wells.

The European Research Council (http://erc.europa.eu/ starting-grants) Starting Grant GLASS (no. 259256) has supported this research. The funding project is called Integrated Laboratories to Investigate the Mechanics of Aseismic vs. Seismic Faulting (GLASS; http://www.roma1.ingv.it/laboratori/ laboratorio-hp-ht/glass-project) and it is hosted at the National Institute of Geophysics and Volcanology (INGV; www.ingv.it) in Rome.

Edited by: T. Wiersberg

Reviewed by: M. J. Jurado and one anonymous referee

\section{References}

Chiaraluce, L. and TABOO working group: The Alto Tiberina Near Fault Observatory (Northern Apenniines, Italy), Ann. Geophys., in review, 2014.

Chiaraluce, L., Chiarabba, C., Collettini, C., Piccinini, D., and Cocco, M.: Architecture and mechanics of an active low angle normal fault: Alto Tiberina Fault, northern Apennines, Italy, J. Geophys. Res., 112, B10310, doi:10.1029/2007JB005015, 2007.

Cocco, M., Montone, P., Barchi, M. R., Dresen, G., and Zoback, M. D.: MOLE: A Multidisciplinary Observatory and Laboratory of Experiments in Central Italy, Sci. Dril., 7, 60-64, doi:10.5194/sd7-60-2009, 2009.

Collettini, C.: The mechanical paradox of low angle normal faults: current understanding and open questions, Tectonophysics, 510, 253-268, 2011.

Collettini, C. and Barchi, M. R.: A low angle normal fault in the Umbria region (central Italy): A mechanical model for the related microseismicity, Tectonophysics, 359, 97-115, 2002.

Collettini, C., Di Stefano, G., Carpenter, B. M., Scarlato, P., Tesei, T., Mollo, S., Trippetta, Marone, C. F., Romeo, G. and Chiaraluce, L.: A novel and versatile apparatus for brittle rock deformation, Int. J. Rock Mech. Mining Sci., 66, 114-123, 2014.

Latorre, D., Lupattelli, A., Mirabella, F., Trippetta, F., Valoroso, L., Lomax, A., Di Stefano, R., Collettini, C., and Chiaraluce, L.: A 3-D velocity model for earthquake location from combined geological and geophysical data: a case study from the TABOO near fault observatory (Northern Apennines, Italy), Vienna, EGU 2014 in SM4.4/GD8.5/TS9.12, 2014.

Mirabella, F., Brozzetti, F., Lupattelli, A., and Barchi, M. R.: Tectonic evolution of a low-angle extensional fault system from restored cross-sections in the Northern Apennines (Italy), Tectonics, 30, TC6002, doi:10.1029/2011TC002890, 2011.

Trippetta, F., Collettini, C., Vinciguerra, S., and Meredith, P. G.: Laboratory measurements of the physical properties of Triassic Evaporites from Central Italy and correlation with geophysical data, Tectonophysics, 492, 121-132, 2010.

Trippetta, F., Collettini C., Barchi, M. R., Lupattelli, A., and Mirabella, F.: A multidisciplinary study of a natural example of a $\mathrm{CO}_{2}$ geological reservoir in central Italy, Int. J. Greenh. Gas Con., 12, 72-83, 2013. 